\title{
Dynamic accommodative response to different visual stimuli (2D vs 3D) while watching television and while playing Nintendo 3DS Console
}

\author{
Sílvia Oliveira, Jorge Jorge and José M González-Méijome \\ Clinical and Experimental Optometry Research Lab, Centre of Physics (Optometry), School of Sciences, University of Minho, Braga, Portugal
}

Citation information: Oliveira S, Jorge J \& González-Méijome JM. Dynamic accommodative response to different visual stimuli (2D vs 3D) while watching television and while playing Nintendo 3DS Console. Ophthalmic Physiol Opt 2012, 32, 383-389. doi: 10.1111/j.1475-1313.2012.00934.x

\begin{abstract}
Keywords: 3D television, accommodative response, Nintendo 3DS, three dimensions

Correspondence: Sílvia Oliveira

E-mail address: moasilvia@gmail.com
\end{abstract}

Received: 06 January 2012; Accepted: 18 July 2012

\begin{abstract}
Purpose: The aim of the present study was to compare the accommodative response to the same visual content presented in two dimensions (2D) and stereoscopically in three dimensions (3D) while participants were either watching a television (TV) or Nintendo 3DS console.

Methods: Twenty-two university students, with a mean age of $20.3 \pm 2.0$ years (mean \pm S.D.), were recruited to participate in the TV experiment and fifteen, with a mean age of $20.1 \pm 1.5$ years took part in the Nintendo 3DS console study. The accommodative response was measured using a Grand Seiko WAM 5500 autorefractor. In the TV experiment, three conditions were used initially: the film was viewed in 2D mode (TV2D without glasses), the same sequence was watched in 2D whilst shutter-glasses were worn (TV2D with glasses) and the sequence was viewed in 3D mode (TV3D). Measurements were taken for $5 \mathrm{~min}$ in each condition, and these sections were sub-divided into ten 30-s segments to examine changes within the film. In addition, the accommodative response to three points of different disparity of one 3D frame was assessed for 30 s. In the Nintendo experiment, two conditions were employed $-2 \mathrm{D}$ viewing and stereoscopic 3D viewing.

Results: In the TV experiment no statistically significant differences were found between the accommodative response with TV2D without glasses $(-0.38 \pm 0.32 \mathrm{D}$, mean \pm S.D. $)$ and TV3D $(-0.37 \pm 0.34 \mathrm{D})$. Also, no differences were found between the various segments of the film, or between the accommodative response to different points of one frame $(p>0.05)$. A significant difference $(p=0.015)$ was found, however, between the TV2D with $(-0.32 \pm 0.32 \mathrm{D})$ and without glasses $(-0.38 \pm 0.32 \mathrm{D})$. In the Nintendo experiment the accommodative responses obtained in modes $2 \mathrm{D}(-2.57 \pm 0.30 \mathrm{D})$ and 3D $(-2.49 \pm 0.28 \mathrm{D})$ were significantly different (paired $t$-test $p=0.03)$.

Conclusions: The need to use shutter-glasses may affect the accommodative response during the viewing of displays, and the accommodative response when playing Nintendo $3 \mathrm{DS}$ in $3 \mathrm{D}$ mode is lower than when it is viewed in 2D.
\end{abstract}

\section{Introduction}

The interest in devices that provide a stereoscopic percept has grown dramatically in the last years. This $3 \mathrm{D}$ experience can be enjoyed almost everywhere and is not limited to the movies, but can be appreciated at home by using 3D televisions, computers or game consoles.

Previous studies report that the viewing of 3D contents may cause some visual symptoms like blurred and double vision and motion sickness-like symptoms including 
headaches, nausea, and dizziness. ${ }^{1-5}$ Being aware of this possibility, device manufacturers advise against their use for prolonged periods by people with personal or family history of epilepsy or migraines, and children under the age of 6 years. ${ }^{6,7}$ Some people only report the presence of symptoms during the viewing of $3 \mathrm{D}$ contents, whilst for others the symptoms persists after the viewing. ${ }^{4}$ In August 2010 the National Consumer Affairs Center of Japan reported five cases of consumers that experienced severe headaches and double vision for a few days after viewing $3 \mathrm{D}$ movies. ${ }^{8}$

Although we live in a three-dimensional world, there are differences between a natural 3D stimulus and the one recreated by using a flat screen. In the first situation, the 'real' world, objects at different distances provide a different stimulus to both the accommodative system and the vergence system, which are determined by the location of the objects. When looking at a real object, the image will generally be in focus, whereas other objects located in front or behind it will be out of focus and diplopic. ${ }^{5}$ The amount of defocus could provide a clue to the distance between objects regarding the plane of fixation. In the second situation, the stereoscopic images are produced on a flat screen, and consequently the accommodative stimulus is fixed, and independent of the geometrical location of the object, be it nearer or further than the plane of the screen. In addition, the relationship between the amount of defocus and the amount of diplopia may be unnatural. ${ }^{5}$

In order to experience stereopsis the image that reaches the right eye must be slightly different from that which reaches the left eye. For most film and television set-ups this is achieved by using anaglyph filters, polarizing filters or active glasses (shutter-glasses). For other devices, such as the Nintendo 3DS, an auto-stereoscopic system is used. For these, there are two types of technology used (1) lenticular and (2) parallax barrier. The latter works better for smaller screens, ${ }^{9}$ and this is the system used in the 3DS consoles.

The cause of the onset of symptoms has been attributed to several factors such as the quality of the 3D images, ${ }^{5,10,11}$ the distance at what they are viewed ${ }^{12}$ and the accommodation and vergence conflicts that may happen when viewing 3D contents. ${ }^{1,5,13,14}$ These two systems interact; the stimulation of one induces a response in the other. ${ }^{15}$ The aim of the current study was to compare the accommodative response when viewing a TV film in $2 \mathrm{D}$ and $3 \mathrm{D}$ modes and when players viewed the Nintendo $3 \mathrm{DS}$ in $2 \mathrm{D}$ and $3 \mathrm{D}$ mode. In the TV experiment, three conditions were used initially: the film was viewed in $2 \mathrm{D}$ mode (TV2D without glasses), the same sequence was watched in $2 \mathrm{D}$ whilst shutter-glasses were worn (TV2D with glasses) and the sequence was viewed in $3 \mathrm{D}$ mode (TV3D). Measurements were taken for $5 \mathrm{~min}$ in each condition, and these sections were sub-divided into ten 30-s segments to examine changes within the film. Such changes could be expected because different portions of the film will contain images at different depths. In addition, the accommodative response to three points of different disparity of one 3D frame was assessed for $30 \mathrm{~s}$. In the Nintendo experiment, two conditions were employed $-2 \mathrm{D}$ viewing and $3 \mathrm{D}$ viewing.

\section{Methods}

Six sets of recordings were obtained; four using a TV as the display device and two using the Nintendo 3DS. First, we measured the accommodative response to the $2 \mathrm{D}$ film; second, the accommodative response to the same sequence of the $2 \mathrm{D}$ film was measured whilst the observers wore $3 \mathrm{D}$ shutter glasses; third, we measured the response to the same sequence when the film was shown in stereoscopic 3D. The fourth set of measurements were taken when the observers fixated three different points from a single frame, one located in front of the TV screen, one on the screen and one behind it. The remaining two sets of measurements were taken when the Nintendo 3DS was used in 2D and in 3D stereoscopic mode.

\section{Participants}

Twenty-two university students (six male, 16 female), with ages ranging from 17 to 25 years $(20.3 \pm 2.0$ years, mean \pm S.D.) participated in the TV experiment. Fifteen university students (11 females, four males), with ages ranging from 17 to 23 years $(20.1 \pm 1.5$ years $)$, participated in the 3DS console experiment.

All optometric tests were made by an experienced optometrist. The participants were required to have good uncorrected visual acuity of at least $0.0 \log$ MAR ((Snellen $6 / 7.5$ or 20/25) in each eye for distance vision and the equivalent of $0.0 \log$ MAR (Snellen $6 / 6$ or 20/20) for near vision). Their phorias were all compensated by fusional reserves, all had normal near point of convergence $(5 \pm 2 \mathrm{~cm})^{16}$ and an AC/A ratio and binocular accommodative amplitude both of which were normal for their age. All had stereopsis of $50 \mathrm{~s}$ of arc or better, assessed by Titmus Stereo Test (http://www.stereooptical.com). None had a personal or familiar history of epilepsy or migraine. Following the tenets of the Helsinki Declaration, after all of the procedures were explained the subjects signed an informed consent form and were then enrolled onto the study.

\section{Equipment}

\section{TV experiment.}

The 4th part of the film 'Monsters vs Aliens' (www. dreamworksanimation.com) was used to compare the 
accommodative response when watching the film on TV in 2D (LCD TV 32LG2100 LG, www.lg.com) and in 3D (LCD TV LE40C75 Samsung, www.samsung.com). The accommodation response was measured using a Grand Seiko WAM 5500 autorefractor ${ }^{17,18}$ (Grand Seiko, http:// www.grandseiko.com) in the continuous acquisition mode attached to a custom software to record the refractive power of the eye at $3 \mathrm{~Hz}$ with a resolution of $\pm 0.01 \mathrm{D}$.

\section{Console experiment.}

The accommodative response while playing Nintendo $3 \mathrm{DS}$ in a $2 \mathrm{D}$ (two dimensions) mode with the one that occurs when playing in 3D (three dimensions) mode was measured while using the sequence 'Landing at Sea' of the PilotWing Resort game for Nintendo 3DS. Accommodation was again measured using the Grand Seiko autorefractor.

\section{Procedure}

Subjects sat behind the autorefractor and the chair height and chin rest were adjusted for individual comfort whilst they were viewing the TV or the console. Ambient lighting was kept constant at 20 lux for all experiments. All measures were taken in the observer's dominant eye (determined by the Dolman method ${ }^{19}$ ). The TV experiment and the Console experiment were performed on different days.

\section{TV experiment.}

The accommodative response was first measured in $2 \mathrm{D}$ mode (TV2D without glasses) for a period of $5 \mathrm{~min}$. Next, shutter-glasses were used for viewing the same scene in $2 \mathrm{D}$ (TV2D with glasses) and the accommodative response was measured for the same length of time. Participants then viewed the same scene on the 3D TV for $5 \mathrm{~min}$, using the same shutter glasses. The distance between the television and the corneal plane of the observers was kept constant at $2 \mathrm{~m}$ for all experiments. At the end of each sequence of measures, subjects took a break of at least $5 \mathrm{~min}$, and avoided doing any near vision tasks.

To evaluate the sensitivity of the accommodative system to the location of virtual 3D points with different disparities, a frame found $10 \mathrm{~min}$ and $54 \mathrm{~s}$ into the movie was used (Figure 1). The participants were instructed to fixate a point ' $A$ ', virtually located at $33 \mathrm{~cm}$ in front of the screen, a point ' $\mathrm{B}$ ' in the screen and a point ' $\mathrm{C}$ ' virtually located at $49 \mathrm{~cm}$ behind the screen. Measures were collected for $30 \mathrm{~s}$ for each point. The geometric locations of images formed in front and behind the screen were calculated for an interpupillary distance of $60 \mathrm{~mm}^{20}$ (mean of all subjects).

All measures for the TV experiment were taken on the same day. The sequence of presentations was not ran-

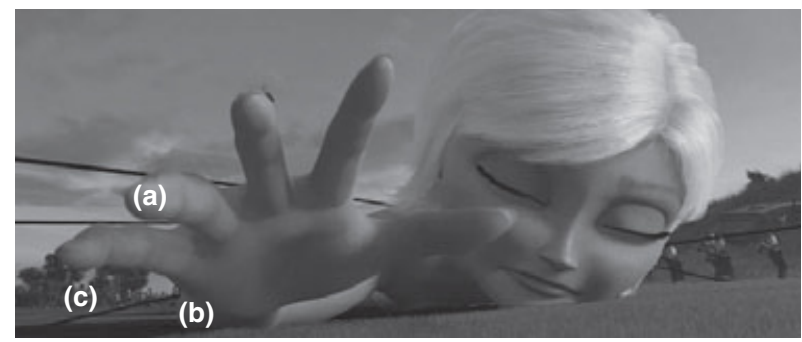

Figure 1. 'Monsters vs Aliens' movie (frame corresponding to $10 \mathrm{~min}$ and 54 s). (a) Point in front of the screen. (b) Point in the screen. (c) Point behind the screen.

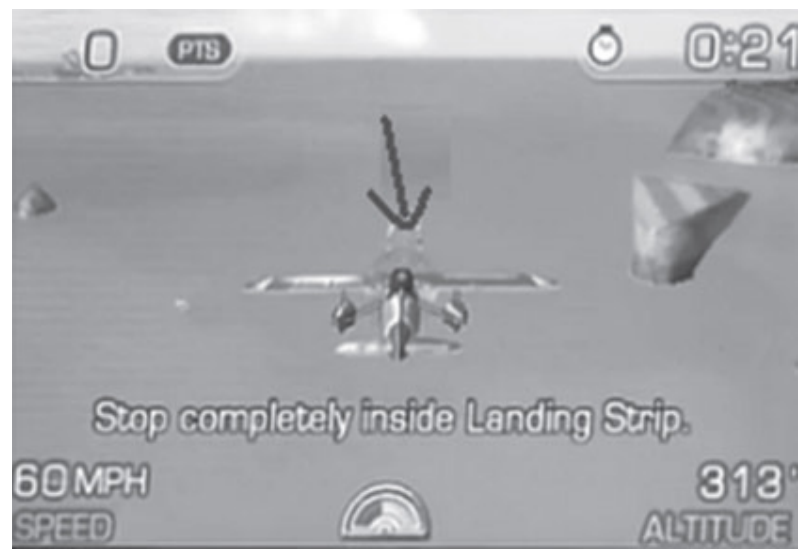

Figure 2. 'Pilotwing Resort' game - sequence 'Land at the Sea' for Nintendo 3DS.

domised because of difficulties in changing the experimental setups.

\section{Console experiment.}

The console game Nintendo 3DS was positioned at $33 \mathrm{~cm}$ from the corneal plane of the observer. The observer kept an airplane flying by using the circle pad button and by keeping their attention on the helix plane (arrowed in Figure 2), for a period of $5 \mathrm{~min}$, during which time their accommodation was monitored. The order of presentation was randomised. The two measurements were taken on the same day with an interval of $5 \mathrm{~min}$ at least between each one.

\section{Statistical analysis}

To analyze the data, the periods of 5 min were divided in 10 intervals of $30 \mathrm{~s}$. The accommodative response of each subject was filtered offline to remove measurement artefacts due to blinks and fixations losses: values above or below three standard deviations from the mean were eliminated before the data were analysed further. ${ }^{21}$ The mean of each interval was computed from the means of all 
subjects for that interval. The SPSS statistical package v.18 (http://www.ibm.com/software/analytics/spss) was used to conduct the statistical analysis. The Shapiro-Wilk test was applied to evaluate the normality of data distribution, and because none of the variables had a non-normal distribution, parametric tests were then used. ANOva was performed to evaluate the stability of the accommodative response for the period of $5 \mathrm{~min}$ and to compare the accommodative response to points with different disparities in the same frame. The comparison between the experiments TV2D without glasses, TV2D with glasses and TV3D as well as between 2D ad 3D for the Nintendo experiment were performed by using paired-sample $t$-tests.

\section{Results}

\section{TV experiment}

For each of the three conditions tested (watching the film in $2 \mathrm{D}$ with and without the shutter glasses and in 3D mode) the average accommodative response appeared to be constant over the period of $5 \mathrm{~min}$. The three panels of Figure 3 display the results obtained when subjects viewed a film in $2 \mathrm{D}$ without shutter-glasses, in $2 \mathrm{D}$ with shutterglasses and in 3D for a period of $5 \mathrm{~min}$ split into $30 \mathrm{~s}$ intervals, respectively. To evaluate the stability of the response, an ANOVA was performed and no statistical differences were found for the 10 intervals in any condition (TV2D without glasses $p=0.99 ;$ TV2D with glasses $p=1.0 ; \operatorname{TV} 3 \mathrm{D} p=1.0$ ).

Figure 4 displays the average accommodative response over the $5 \mathrm{~min}$ interval for the experiment TV2D without glasses $(-0.38 \pm 0.32 \mathrm{D}$, mean \pm S.D. $)$ TV2D with glasses $(-0.32 \pm 0.32 \mathrm{D})$ and TV3D $(-0.37 \pm 0.34 \mathrm{D})$. Statistically significant differences were found when comparing the accommodative response when using, and not using, the shutter-glasses while viewing the film $(p=0.015)$. Differences were not statistically significant between viewing the same sequence of film in 2D (without shutter-glasses) or in $3 \mathrm{D}$ mode $(p=0.43)$.

Figure 5 displays the results when observers were asked to fixate a point virtually located in front of the screen $(-0.42 \pm 0.34 \mathrm{D}$, mean \pm S.D. $)$, one in the screen $(-0.41$ $\pm 0.39 \mathrm{D})$ and a point virtually located behind the screen $(-0.34 \pm 0.42 \mathrm{D})$. Although the rank order of these results is as expected, the differences are small and did not reach statistical significance $(p=0.74)$.

\section{Console experiment}

Figure 6 shows the average accommodative response for the $5 \mathrm{~min}$ trial while playing for $5 \mathrm{~min}$ with the Nintendo $3 \mathrm{DS}$ in $2 \mathrm{D}(-2.57 \pm 0.30 \mathrm{D}$, mean \pm S.D. $)$ and in $3 \mathrm{D}$ $(-2.49 \pm 0.28 \mathrm{D})$ modes. The accommodative response
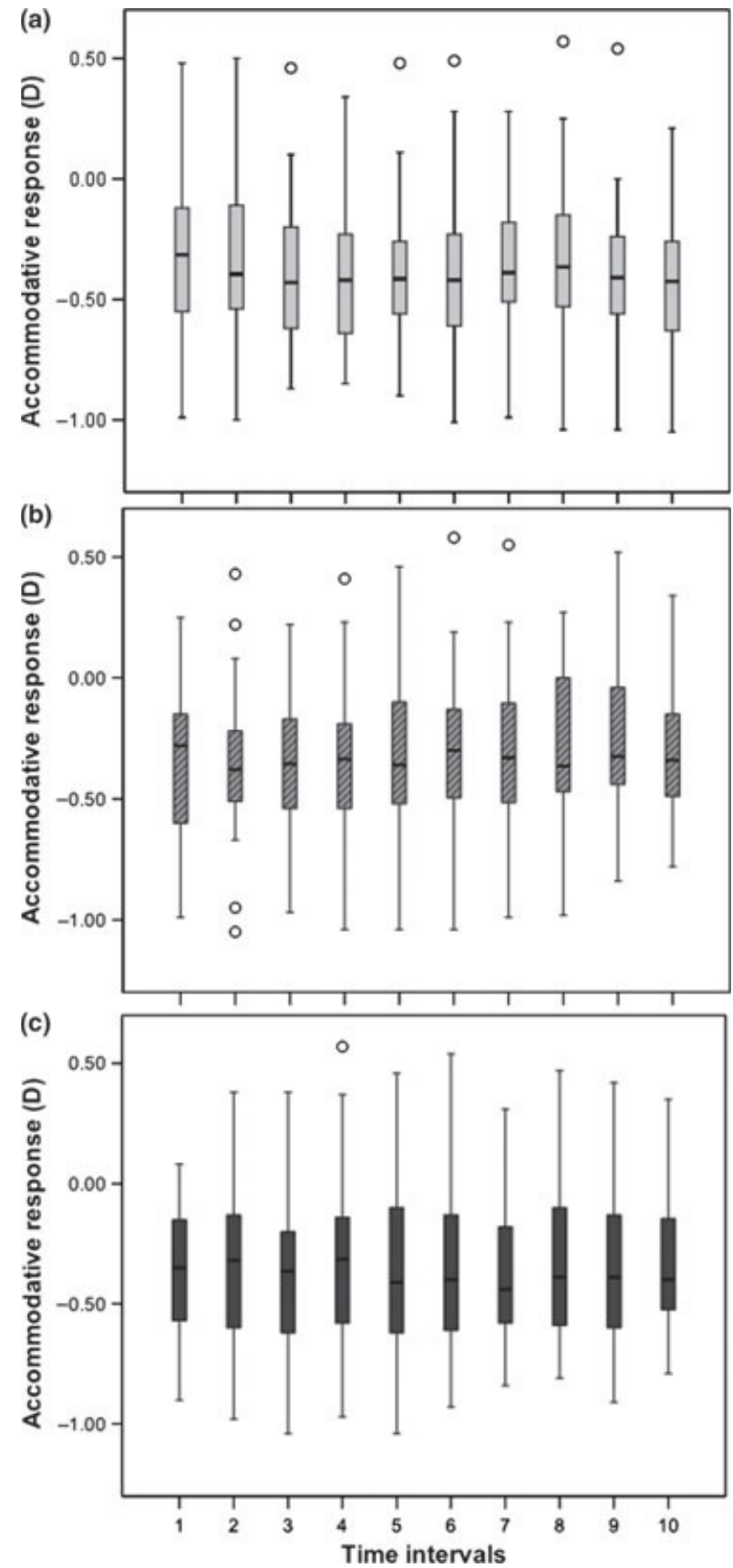

Figure 3. Accommodative response for a period of $5 \mathrm{~min}$ while viewing: (a) 2D movie without shutter-glasses; (b) 2D movie with shutterglasses; (c) 3D movie (Negative values represent a myopic shift in refraction as measured with the Grand Seiko WAM5500 as the patient accommodates for near targets).

was higher when playing in 2D mode, and this difference was statistically significant $(p=0.03)$. The difference was consistent over the whole $5 \mathrm{~min}$ period, as shown in Table 1. 


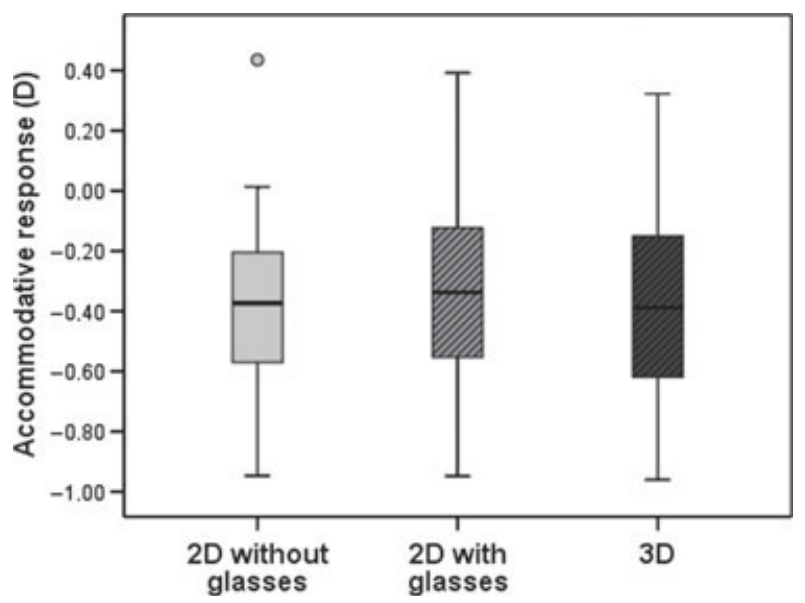

Figure 4. Accommodative responses for the 2D film (without and with shutter-glasses) and 3D film (Negative values represent a myopic shift in refraction i.e. increased accommodation).

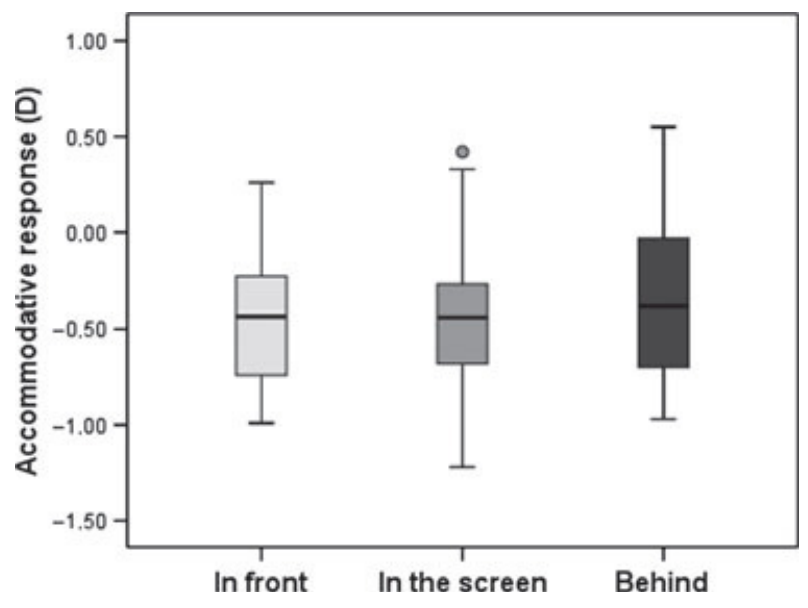

Figure 5. Accommodative responses for the three points shown in Figure 1 which have different disparities (Negative values represent an increase in accommodation).

\section{Discussion}

The primary aim of the experiment was to compare the accommodative response when participants viewed a moving visual image presented in $2 \mathrm{D}$ and stereoscopic $3 \mathrm{D}$ forms. Both forms were presented in two different ways, on television and using a Nintendo 3DS.

Considering the TV stimulus first, it was necessary to use shutter-glasses when using the $3 \mathrm{D} \mathrm{TV}$ and so the influence of these glasses on the accommodative response was investigated. When comparing the film in $2 \mathrm{D}$ mode, there were statistically significant differences $(p=0.015)$ between the two conditions of wearing/not wearing the shutter glasses, with a lower accommodative response

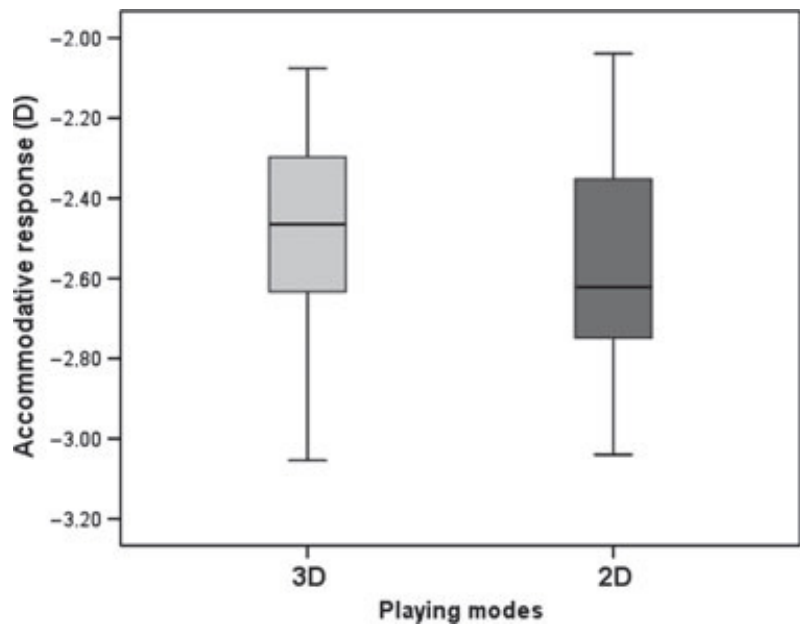

Figure 6. Accommodative responses for the 2D and 3D playing modes (Negative values show an increase in accommodation).

Table 1. The mean, standard deviation and the level of statistical significance of the accommodative response measurement in 10 different time periods, for 2D and 3D stereoscopic mode in the Nintendo 3DS experiment

\begin{tabular}{|c|c|c|c|}
\hline & Nintendo 2D & Nintendo 3D & \\
\hline Time intervals & Mean \pm S.D. & Mean \pm S.D. & Significance $(p)$ \\
\hline $1(0-30 \mathrm{seg})$ & $-2.58 \pm 0.30$ & $-2.49 \pm 0.29$ & 0.083 \\
\hline 2 (31-60 seg) & $-2.58 \pm 0.32$ & $-2.51 \pm 0.27$ & 0.12 \\
\hline 3 (61-90 seg) & $-2.59 \pm 0.31$ & $-2.48 \pm 0.27$ & $0.006^{*}$ \\
\hline $4(91-120 \mathrm{seg})$ & $-2.59 \pm 0.31$ & $-2.48 \pm 0.31$ & $0.012^{*}$ \\
\hline $5(121-150 \mathrm{seg})$ & $-2.59 \pm 0.31$ & $-2.48 \pm 0.30$ & $0.011 *$ \\
\hline $6(151-180 \mathrm{seg})$ & $-2.56 \pm 0.30$ & $-2.46 \pm 0.28$ & 0.020 * \\
\hline $7(181-210 \mathrm{seg})$ & $-2.55 \pm 0.30$ & $-2.49 \pm 0.31$ & 0.10 \\
\hline $8(211-240 \mathrm{seg})$ & $-2.55 \pm 0.32$ & $-2.50 \pm 0.30$ & 0.19 \\
\hline 9 (241-270 seg) & $-2.57 \pm 0.33$ & $-2.48 \pm 0.32$ & $0.036^{*}$ \\
\hline $10(271-300 \mathrm{seg})$ & $\begin{array}{l}-2.56 \pm 0.30 \\
p=1.0^{*}\end{array}$ & $\begin{array}{l}-2.48 \pm 0.32 \\
p=1.0 *\end{array}$ & $0.012^{*}$ \\
\hline
\end{tabular}

Values in dioptres - *ANOVA post-hoc bonferroni.

when they were worn. The results found in the $3 \mathrm{D}$ stereoscopic mode, with the glasses worn, were between these two values, but were not statistically significantly different from either (and were almost identical to the $2 \mathrm{D}$ without glasses average). The use of shutter-glasses reduces the amount of light that reaches the eyes but it does so in different ways in the two conditions we ran. In the 3D condition the shutter glasses were synchronised with the $\mathrm{TV}$ and so each eye only saw the one image. In the 2D condition the glasses were triggered by the infra-red signal from an adjacent 3D TV and so were not in synchrony with the 2D TV display, and this could have affected the accommodation response. 
It is well known that watching film in $3 \mathrm{D}$ may lead to the manifestations of symptoms that are of concern to the users. In the next part of the study we aimed to evaluate how the accommodative system responds when the images are not always at the same geometric distance from the observer. We found that the accommodative response to the 3D film was not significantly different from that measured when the film was viewed in $2 \mathrm{D}$ mode $(p=0.43)$ at least for the sequence tested, in which the most of the images were located in the screen or behind it, for the period of $5 \mathrm{~min}$. Yang et al., ${ }^{2}$ conducted a similar experiment, but during a different time period, they measured the accommodative response for a period of $90 \mathrm{~min}$ and divided the period into five intervals, and found statistically significant differences in the accommodative response for some intervals tested. In the present study no statistical differences were found when comparisons were made over $30 \mathrm{~s}$ intervals, and this was true for every interval.

With respect to the points viewed which had different disparities, no significant differences were found for the accommodative response for the three different points evaluated in the same $3 \mathrm{D}$ fixed scene $(p=0.74)$. Having said this, it is worth noting that the rank order of the three is as one would expect on the basis of the accommodation produced by convergence-accommodation. Considering this, the results might not be surprising as all of them might be within the depth of focus of the observer and thus no conflicts between the accommodation and vergence systems are expected. It is also worth noting that all three points are located in the zone of comfortable vision. ${ }^{12}$

Turning now to the results found when the images were displayed on a Nintendo 3DS. This device was launched in March 2011, and was the first portable console game that allowed users to play in $3 \mathrm{D}$ without the need of special glasses. When playing in 3D mode the stereoscopic images which are at a different depth are all virtually located behind the screen: the game console only allows images in uncrossed disparity. In this experiment we aimed to compare the accommodative response in two extreme situations: when playing in $2 \mathrm{D}$ mode in which the images are located in the screen $(33 \mathrm{~cm}$ from observers corneal plane), and in 3D stereoscopic mode. In both situations subjects were asked to keep their attention in the helix plane, which was located geometrically $3.1 \mathrm{~cm}$ behind the screen in the $3 \mathrm{D}$ stereoscopic mode. ${ }^{20}$ Consistent with the expectation on the basis of the stimulus, the $3 \mathrm{D}$ stereoscopic mode produced less accommodation than the $2 \mathrm{D}$ mode, and the difference was statistically significant $(p=0.03)$. The difference between the two situations is $0.08 \mathrm{D}$, and in clinical terms this difference has no great significance and would be the equivalent of playing at
$1 \mathrm{~cm}$ further away from the initial position. If we take into account the virtual location of the helix plane in $3 \mathrm{D}$ mode one might have expected a larger effect. We might bear in mind that users tend to play for more than just $5 \mathrm{~min}$, so it could be useful to see if the results remain the same when playing for longer periods of time.

Previous studies have shown that people with binocular dysfunction may be more susceptible to having symptoms associated with viewing $3 \mathrm{D}$ contents. ${ }^{22,23}$ Mainos $^{24}$ reported that accommodative and vergence dysfunctions can lead to the manifestation of symptoms in users when watching $3 \mathrm{D}$ contents and that the improvement in binocular vision by visual therapy may reduce its manifestation. Kim et al., ${ }^{25}$ demonstrated that the use of binocular vision corrective spectacles can reduce the manifestation of symptoms when viewing 3D contents. The results found in our experiments may have been different had the sample included people with binocular vision problems. Another aspect that may have limited our results in both of the viewing types (TV and 3DS) is the short period tested. People tend to spend more than just $5 \mathrm{~min}$ watching films or playing with console games.

In summary, our results suggest that potential complaints from 3D users either with TV displays or console gaming cannot be explained solely on the basis of abnormal accommodative responses.

\section{Acknowledgements}

Thanks to Dr. Peter Howarth for his editorial assistance. Thanks to Dr. António Queirós for the support in preparing the experimental setup.

None of the authors has an interest in the products and devices mentioned in the study. This study has been funded by projects PTDC/SAU-BEB/098392/2008 funded by the Portuguese Fundação para a Ciência e Tecnologia through the European Social Fund.

\section{References}

1. Lambooij M, IJsselsteijn W, Fortuin M \& Heynderickx I. Visual discomfort and visual fatigue of stereoscopic displays: a review. J Imaging Sci Technol 2009; 53: 030201030214.

2. Yang S-N \& Sheedy JE. Effects of vergence and accommodative response on viewer's comfort in viewing stereoscopic stimuli. Proc SPIE 2011; 7863: 78630Q78630Q-13.

3. Häkkinen J, Pölönen M, Takatalo J \& Nyman G. Simulator sickness in virtual displays gaming: a comparison of stereoscopic and non-stereoscopic situations. Proceedings of the 8th Conference on Human-Computer Interaction with Mobile Devices and Services. New York, 2006: 227-230. 
4. Yang S, Schlieski MA, Schlieski T, Selmins B, Cooper S, Doherty R, Corriveau PJ, Sheedy JE. Immersion and Symptoms in 3D Viewing. Optom Vis Sci 2012; 89: 10681080 .

5. Howarth PA. Potential hazards of viewing 3-D stereoscopic television, cinema and computer games: a review. Ophthalmic Physiol Opt 2011; 31: 111-122.

6. Samsung - important health and safety information for 3D pictures. http://www.samsung.com/au/tv/pdf/Viewing3D-TV-Notice.pdf, accessed 29/12/2011.

7. Nintendo 3DS - health \& safety precautions. http:// www.nintendo.com/consumer/systems/3ds/en_na/health_ safety.jsp, accessed 29/12/2011.

8. Bando T, Iijima A \& Yano S. Visual fatigue caused by stereoscopic images and the search for the requirement to prevent them: a review. Displays 2011; 33: 76-83.

9. Kunic S \& Sego Z. 3D Television. IEEE Conference Publications: 2011; pp. 127-131.

10. Kooi FL \& Toet A. Visual comfort of binocular and 3D displays. Displays 2004; 25: 99-108.

11. Lambooij M., IJsselsteijn WA \& Heynderickx I. Visual discomfort of 3-D TV assessment methods and modelling. Displays 2011; 32: 209-218.

12. Shibata T, Kim J, Hoffman DM \& Banks MS. The zone of comfort: predicting visual discomfort with stereo displays. $J$ Vis 2011; 11: 11 .

13. Hoffman DM, Girshick AR, Akeley K \& Banks MS. Vergence-accommodation conflicts hinder visual performance and cause visual fatigue. $J$ Vis 2008; 8: 33.

14. Ukai K \& Howarth PA. Visual fatigue caused by viewing stereoscopic motion images: Background, theories, and observations. Displays 2008; 29: 106-116.

15. Schor C. The influence of interactions between accommodation and convergence on the lag of accommodation. Ophthalmic Physiol Opt 1999; 19: 134-150.
16. Scheiman M, Gallaway M, Frantz KA et al. Nearpoint of convergence: test target selection, and normative data. Optom Vis Sci 2003; 80: 214-225.

17. Davies LN \& Sheppard AL. Clinical evaluation of the Grand Seiko Auto Ref/Keratometer Wam-5500. Ophthalmic Physiol Opt 2010; 30: 143-151.

18. Win-Hall DM, Houser J \& Glasser A. Static and dynamic accommodation measured using the WAM-5500 autorefractor. Optom Vis Sci 2010; 87: 873-882.

19. Li J, lam CSY, Yu M et al. Quantifying sensory eye dominance in the normal visual system: a new technique and insights into variations across traditional test. Invest Ophthalmol Vis Sci 2010; 51: 6875-6881.

20. Holliman N. Mapping Perceived Depth to Regions of Interest in Stereoscopic Images. http://www.dur.ac.uk/n.s. holliman/Presentations/EI5291A-12.pdf, accessed 24/4/2012.

21. Kundart J, Tai YC, Hayes JR, Gietzen J \& Sheedy J. Real-time Objetive Measurement of Accommodation while Reading. Vision Ergonomics Laboratory Pacific University: Forest Grove, OR, 2010. http://commons.pacificu.edu/verg/4/, accessed 11/10/2011.

22. Lambooij M, Fortui M, IJsselsteijn WA, Evans BJ \& Heynderickx I. Measuring visual discomfort associated with 3-D displays. J Soc Inform Displays 2010; 18: 931-943.

23. Lambooij M, IJsselsteijn WA, Fortuin M, Evans BJ \& Heynderickx I. Susceptibility to visual discomfort of 3-D displays by visual performance measures. IEEE Trans Circuits Syst Video Technol 2011; 21: 1913-1923.

24. Maino D. The 3D Vision Syndrome: A Case Report. http:// www.slideshare.net/DMAINO/3d-vision-syndrome, accessed 20/3/2012.

25. Kim J, Yoon JH \& Ciuffreda KJ. Binocular vision corrective spectacle lenses reduce visual fatigue in 3-D television viewing. ARVO Meeting Abstracts March 26, 2012; 53: 1780. 